\title{
Law and University Efficiency: The Amendment of the
}

\section{University Law in Taiwan}

\author{
Rong-Ruey Duh ${ }^{1}$, Jenn-Shyong Kuo ${ }^{2}$ \\ ${ }^{1}$ Department of Accounting, National Taiwan University \\ ${ }^{2}$ Department of Accounting, National Taipei University
}

\begin{abstract}
This paper examines the effect of the amendment of an education-related law on university efficiency using the 1994 University Law amendment in Taiwan as a case study. The results indicate that prior to the 1994 amendment; private universities operate in a more efficient manner than public universities. This difference disappears a year after the amendment, but the beneficial effect of this amendment on public universities diminishes two years after the amendment. The finding indicates that the recent (2005) amendment is in a right direction concerning the size and authority of university senate.
\end{abstract}

Keywords: Educational economics; Efficiency; Data envelopment analysis, University Law

\section{Introduction}

Like any other organization, universities operate in environments where laws and regulations impose restrictions on organizational discretions in an attempt to maintain the operations of higher education institutions in an orderly fashion. The amendment of related laws or regulations will thus have impacts on the operations of universities.

After some 11 years of the last amendment, the University Law underwent another major amendment in 2005. The last amendment (hereafter the 1994 amendment) of the University Law in Taiwan was passed and announced after eight years of deliberation. Since then, the universities could decide for themselves on organizing, staffing, curriculum design, faculty recruiting and diversification of academic fields. Public universities could also participate in the appointment of presidents. The university senate became the highest unit of decision-making. This amendment "critically changed the operations of higher education institutions" (Higher Education Policy White Paper 2001) and should have impacts on university efficiency. And yet, prior to the recent amendment, no research has been conducted to assess the effect of the 1994 amendment. This paper aims at filling the gap. Such an examination can also provide a basis for evaluating the recent (2005) amendment.

Ahn, Charnes and Cooper (1988) conduct data envelopment analysis (DEA) and find that technical efficiency of public universities is higher than that of private universities (cf. Lindsay 1976). But the result is reverse for universities with medical school. Rhodes and Southwick's (1993) DEA indicates that public universities are less efficient than private universities presumably due to public universities' reliance on tax monies for funding.

That public universities are funded by government has two consequences. One is that public universities lack financial pressure and thus incentives to increase efficiency (Rhodes and Southwick 1993). The other is that public universities are subject to more restrictions than private universities in input and output behavior. Laws, regulations and mandated rules stipulate these restrictions to ensure that public universities' behavior is in control. This approach to control, however, does not consider the specific situations (e.g., human capital quality, information and knowledge) that each individual university encounters.

In addition, when asked to supply information to the regulators for making decisions, individual universities may hide some possessed information or delay reporting, thus making regulators lack complete and timely information that each university possesses in making central decisions. Lack of information and adaptability has been suggested as possible reasons for Xinefficiency of organizations (Levine 1997). Moreover, central decision makers may be subject to bounded rationality (Simon 1956). Thus, it is expected that private universities in Taiwan were more efficient than public ones prior to the 1994 amendment. The 1994 amendment enlarges room for universities to use 
the information and knowledge to make timely decisions that are specific to the situations that each university faces. Public universities are subject to less restriction than before and can better use their human capital that has been perceived to be higher than their private counterparts. Thus, the efficiency difference between private and public universities will be reduced after the amendment.

\section{Research Design}

This paper adopts DEA to investigate university efficiency before and after the 1994 amendment of the University Law by comparing technical efficiency of public universities with that of private universities.

Following Charnes, Cooper and Rhodes (1978), the input-oriented technical efficiency index is defined as follows. Suppose that for each time period we can observe $\mathrm{k}(=1,2, \ldots, \mathrm{K})$ universities using inputs vector $x \in R_{+}{ }^{N}$ to produce output vector $y \in R_{+}{ }^{M}$. The production technology for period $t$ can be written as a production possibility or transformation set: $G R=\{(x, y): x$ can produce $y\}$. An alternative way is to define technology as an input requirement set: $\mathrm{L}(y \mid \mathrm{C}$, $\mathrm{S})=\{x:(x, y) \in G R\}$.

Assuming $G R$ satisfies constant return to scale (C) and strong disposability of inputs (S). Following Shepard (1970), the input-oriented distant function is:

$\mathrm{D}_{\mathrm{I}}(y, x \mid C, S)=\min \{\theta:(x / \theta, y) \in(\mathrm{GR} \mid \mathrm{C}, \mathrm{S})(1)$

Following Farrell (1957), the efficiency can be explained in raidal or equiproportional way. The radial input efficiency measure (which is the reciprocal of the $(\mathrm{C}, \mathrm{S})$ input-oriented distant function) is defined as:

$$
\begin{aligned}
\mathrm{F}_{\mathrm{I}}(y, x \mid C, S) & =\min \{\lambda: \lambda x \in \mathrm{L}(y \mid \mathrm{C}, \mathrm{S}) \\
& =\left(\mathrm{D}_{\mathrm{I}}(y, x \mid C, S)\right)^{-1}
\end{aligned}
$$

It indicates that the reciprocal of maximum amount inputs decreases, given the outputs $(y)$. Therefore $\mathrm{D}_{\mathrm{I}}(y, x \mid C, S) \geq 1\left(\mathrm{~F}_{\mathrm{I}}(y, x \mid C, S) \leq 1\right)$ if and only if $(y, x) \in \mathrm{L}(y \mid \mathrm{C}, \mathrm{S}) . \mathrm{D}_{\mathrm{I}}(y, x \mid C, S)=1$ $\left(\mathrm{F}_{\mathrm{I}}(y, x \mid C, S)=1\right)$ if and only if this university is at the boundary of efficiency production.

Technical efficiency of universities can be calculated by using linear programming to solve piecewise linear programming problem of equations (2). The input measure of technical efficiency is calculated as the solution to the linear programming problem.

$$
\mathrm{F}_{\mathrm{I}}\left(y^{\mathrm{k}^{\prime}}, x^{\mathrm{k}^{\prime}} \mid \mathrm{C}, \mathrm{S}\right)=\min _{\lambda, \mathrm{z}} \lambda^{\mathrm{k}^{\prime}}
$$

$$
\begin{aligned}
\text { s.t. } y_{\mathrm{m}}{ }^{\mathrm{k}} \leq \sum_{\mathrm{K}} z^{\mathrm{k}} y_{\mathrm{m}}{ }^{\mathrm{k}}, \mathrm{m}=1,2, \ldots, \mathrm{M} \\
\sum_{\mathrm{K}} x_{\mathrm{n}}{ }^{\mathrm{k}} \leq \lambda^{\mathrm{k}^{\prime}} x_{\mathrm{n}}{ }^{\mathrm{k}^{\prime}}, \mathrm{n}=1,2, \ldots, \mathrm{N} \\
\mathrm{z}^{\mathrm{k}} \geq 0, \quad \mathrm{k}=1,2, \ldots, \mathrm{K}
\end{aligned}
$$

The weight $z$ is determined in such a way that the efficiency $(\lambda)$ of each university is minimized. This set of constraints dictates that neither output, nor the input of university k can excess the frontier. The input orientated technical efficiency, takes on values between 1 and 0 with higher value representing higher efficiency.

Wilcoxon Rank test is used to investigate whether public universities' technical efficiency significantly differs from that of private universities before and after the 1994 amendment of the University Law.

\section{Sample}

This study utilizes cross sectional data for a sample of 47 universities, including 27 public universities and 20 private universities, with observations of inputs and outputs in three academic years from 1993 to 1995 . The data for this study are collected from annual reports of the Ministry of Education and its financial statements.

\section{Input variables}

In this paper, we include the following as input measures:

1. the number of full-time faculty;

2. the number of part-time faculty;

3. the number of administrative staff;

4. number of square meters of building;

5. the number of books of library ; and

6. aggregate operating expenditure exclude salary.

The first three measures are labor inputs; the next two measures are capital inputs, and the last one represents energy, materials and others. Universities use inputs as represented by these measures to perform teaching, research, and public service functions.

\section{Output variables}

Previous studies of higher education such as Ahn, Charnes and Cooper (1988), Ahn, Arnold, Charnes and Cooper (1989), and Førsund and Kalhagen (1999) use proxy variables to measure outputs of higher education institutions because it is difficult to measure outputs. In the present study, outputs of these activities are measured using the following proxy variables.

1. the number of undergraduate student enrolled; 
2. the number of doctoral program students enrolled;

3. the number of master program students enrolled;

4. the number of research projects competed. Since public services include a variety of activities and are difficult to measure, we do not include them in the analysis. In fact, some research projects may be regarded as part of public services. And, outputs of continuing education may also be regarded as a kind of public service. Table 1 provides descriptive statistics for inputs and outputs measures respectively.

\section{Empirical Results}

This study utilizes cross sectional data of a sample of 47 universities for the 1993, 1994 and 1995 academic years. Table 2 presents descriptive statistics of technical efficiency in a particular year. Average technical efficiency of private universities is higher than that of public universities.

The Wilcoxon test (Table 3) indicates that private universities' technical efficiency is significantly higher than that of public universities for 1993 ( $p<0.10$, two-tailed) and $1995(\mathrm{p}<0.10$, two-tailed), but not for $1994(\mathrm{p}=$ $0.2167)$. These findings seem to suggest that prior to the 1994amendment, private universities operated in a more efficient manner than public universities. This difference disappeared a year after the amendment, but the beneficial effect of this amendment to public universities seemed to diminish two years after the amendment.

Further, this study decomposes teaching outputs into engineering/science program and social science program, and obtains results similar to those presented in Tables 2 and 3.

We use the notion of rational expectations to explain the rapid improvement. The amendment of the University Law had been deliberated in the administrative and legislative sectors for eight years prior to its passage in 1994. The universities may have known the basic idea of promoting autonomy and preliminary articles proposed in the amendment, and thus prepared for adjustments to this amendment.

Consequently, once the amendment was passed, universities could rapidly capture the benefit from the expected and enlarged areas of discretion.

However, promoting autonomy may be a two-edged sword. University autonomy since then has been implemented in a way such that nearly all decisions are made through democratic processes. University presidents cannot take actions until they are passed at the senate, which consists of faculty members holding administrative positions, representatives from faculty, administrative staff and students. As the size of meetings increases, the efficiency will suffer (Weingast, Shepsle, and Johnsen 1981).

Similar situations occur at the college and department levels. The frequency of meetings is increased, which may distract faculty from teaching and research activities. The prolonged meetings further deteriorate efficiency and productivity. This may explain why the beneficial effect diminished two years after the amendment. In fact, some scholars have voiced concerns over the inefficiency caused by the operation of university autonomy and democracy, including Tien, the late president of University of California at Berkeley (United Daily News 1997).

Using the above findings to evaluate the recent (2005) amendment of the University Law suggests that the changes in the size and authority of university senate as indicated in article 15 of the 2005 amendment are in the right direction. This article explicitly stipulates that the heads of academic and administrative departments are not necessarily members of university senate and that the senate is no longer the highest unit of decision making. These changes to university senate may enhance university efficiency.

Table 1 : Mean of inputs and outputs variables

\begin{tabular}{lrrrrrr}
\hline & \multicolumn{3}{c}{ public universities } & \multicolumn{2}{c}{ private universities } \\
\hline & 1993 & 1994 & 1995 & 1993 & 1994 & 1995 \\
\hline the number of full-time faculty & 405 & 419 & 428 & 357 & 375 & 382 \\
the number of part-time faculty & 241 & 218 & 225 & 436 & 408 & 428 \\
the number of administrative staff & 259 & 275 & 270 & 182 & 186 & 196 \\
the number of square meters of building & 175705 & 175705 & 635461 & 84963 & 84963 & 327536 \\
the number of books of library & 366867 & 350589 & 399363 & 233378 & 233695 & 253823 \\
aggregate operating expenditure exclude salary & 773801 & 600733 & 640437 & 802599 & 718237 & 716133 \\
the number of research projects competed & 146 & 194 & 258 & 40 & 58 & 81 \\
the number of doctoral program student enrolled & 250 & 274 & 289 & 43 & 48 & 50 \\
the number of master program student enrolled & 725 & 813 & 861 & 377 & 408 & 447 \\
the number of undergraduate student enrolled & 4085 & 4225 & 4310 & 8238 & 8478 & 8663 \\
\hline
\end{tabular}


Table 2: Descriptive statistics of technical efficiency

\begin{tabular}{ccccr}
\hline $\begin{array}{c}\text { Academic } \\
\text { year }\end{array}$ & \multicolumn{2}{c}{$\begin{array}{c}\text { Private } \\
\text { universities }\end{array}$} & \multicolumn{2}{c}{$\begin{array}{c}\text { Public } \\
\text { universities }\end{array}$} \\
\hline & Mean & $\begin{array}{c}\text { Standard } \\
\text { deviation }\end{array}$ & Mean & $\begin{array}{c}\text { Standard } \\
\text { deviation }\end{array}$ \\
\hline 1993 & 0.9601 & 0.0652 & 0.8633 & 0.1878 \\
1994 & 0.9757 & 0.0539 & 0.8883 & 0.1949 \\
1995 & 0.9841 & 0.0364 & 0.8859 & 0.1862 \\
\hline
\end{tabular}

Table 3: Wilcoxon test for differences in technical efficiency between private and public universities

\begin{tabular}{cc}
\hline Academic year & Statistics (p value) \\
\hline 1993 & $1.6848^{*}(0.0920)$ \\
1994 & $1.2353(0.2167)$ \\
1995 & $1.6688^{*}(0.0952)$ \\
\hline Two-tailed tests: *: p-value $<10 \%, * *:$ p- \\
value $<5 \%, * * *:$ p-value $<1 \% 1$.
\end{tabular}

\section{Conclusions and Limitations}

This paper examines the effect of the 1994 amendment of the University Law in Taiwan. The results indicate that prior to the 1994 amendment; private universities operate in a more efficient manner than public universities. This difference disappears a year after the amendment, but the beneficial effect of this amendment on public universities diminishes two years after the amendment.

The findings support that empowering universities through amendment of a major education law can enhance their technical efficiency. This benefit is more evident for public universities, since they are subject to more restrictions prior to the amendment, and thus initially makes the differences in technical efficiency between public and private universities disappear. However, as time elapses, the positive effect diminishes due to the way in which the idea of university autonomy and democracy is implemented. To the extent that our findings are valid, the finding indicates that the recent (2005) amendment is in a right direction concerning the size and authority of university senate.

This study has the following limitations. First, it investigates technical efficiency, but not allocative efficiency due to limitation of price data for inputs and outputs. Second, it does not include measures of output quality. Third, data in this study cover only three years (1993 to
1995) to avoid confounding due to the adoption of University Fund System. Future research may consider extending time periods while controlling for the effects of intervening events.

\section{References}

[1]. Ahn, T., Charnes, A., \& Cooper, W. W. "Some statistical and data evaluations of relative efficiencies of public and private institutions of learning," Socio-Economic Planning Science, 22, 6, 259-269, 1988.

[2]. Ahn, T., Charnes, A., \& Cooper, W. W. "DEA and ratio efficiency analysis for public institutions of higher learning in Texas," Research in Governmental and Nonprofit Accounting, 5, 165-185, 1989.

[3]. Charnes, A., Cooper, W.W. \& Rhodes, E. "Measuring the Efficiency of Decision Making Units," European Journal of Operational Research, 12, 6, 429-444, 1978.

[4]. Farrell, M. J. "The measurement of production efficiency. Journal of the Royal Statistical Society Series," A (3), 253-290, 1957.

[5]. Førsund, F. R., \& Kalhagen, K. O. "Efficiency and productivity of Norwegian colleges," The 1999 International Conference on Efficiency and Productivity Growth, Academia Sinica, Taipei, 1999.

[6]. Levin, H. N. "Raising school productivity: an x-efficiency approach, Economics of Education Review," 16, 3, 303-311, 1997.

[7]. Lindsay, C. M. "A theory of government enterprise," Journal of Political Economy, 84, 5, 1061-1078, 1976.

[8]. Rhodes, E.L. \& Southwick, Jr. L. "Variations in Public and Private University Efficiency," In E. L. Rhodes (Ed.), Applications of management science, Greenwich, Connecticut: JAI Press, Inc. 1993.

[9]. Shephard, R. W. Theory of cost and production functions. Princeton, N.J.: Princeton University Press, 1970.

[10]. Simon, H. "Rational choice and the structure of the environment," Psychological Review, 63, 129-138, 1956.

[11]. United Daily News. "An interview with Chang-Lin Tien and June-Shan Shen on university democracy and deregulation," December 12 (in Chinese). 1997.

[12]. Weingast, B., R., Shepsle, K. A. \& Johnsen, J. "The political economy benefits and costs: A Neoclassical approach to distributive politics," Journal of Political Economy, 89, 642-664. 1981. 